\title{
EL HABLA DE UN "CABALLERO DE LA TIERRA” NOVOHISPANO DEL SIGLO XVI
}

\author{
Ella [Nueva España] fue una en la uida y no \\ más, que primero que se halle otro México \\ y su tierra, nos beremos los pasados y los \\ presentes juntos -en cuerpo y en ánima- \\ delante el señor del mundo aquel día \\ unifersal donde será el juizio final. \\ Juan Suárez de Peralta, Tratado del \\ descubrimiento de las Yndias y su conquista, 1589
}

Es ya consuetudinario, dada la escasez de textos de autores criollos novohispanos, enlistar a escritores españoles como representantes y representativos de la lengua que circulaba en México a lo largo del siglo $\mathrm{XvI}^{1}$. El habla novohispana ha sido, por defecto, cualquier muestra de lengua que se puede documentar sin prestar demasiada importancia al origen de los hablantes/escribientes, dando por sentada una homogeneidad dialectal que, de haber existido, queda por demostrarse. Si es obvio que el primer castellano que circuló por el Caribe y, un poco más tarde, por la Nueva España era el hablado por los conquistadores y sus inmediatos descendientes, junto con el de los eclesiásticos y perso-

${ }^{1}$ Walter D. Mignolo, "El mandato y la ofrenda: la Descripción de la ciudad y provincia de Tlaxcala, de Diego Muñoz Camargo, y las relaciones de Indias", $N R F H, 35$ (1987), 451-484, plantea el problema de la clasificación de textos que, aunque no poseen los atributos necesarios para ser incluidos entre los canónicos, sí tienen interés como "documentos" para los estudios literarios. Para la lingüística textual el problema es similar. El estudioso del castellano en su dimensión histórica, aunque muy consciente de lo que constituye un corpus, se ha visto tradicionalmente limitado a basarse en textos esencialmente pertenecientes al canon literario por ser éstos los únicos fácilmente disponibles. 
nal administrativo que pronto se incorporaría a los inmigrados, no es menos cierto que los criollos que sucedieron a esta primera generación novohispana se sentían ya distintos de sus padres y, lo que es más, eran objeto de escarnio y crítica por parte de los administradores y coetáneos peninsulares, quienes los tildaban de "perdidos". León Romano observaba en 1552:

Los niños mozos desta nuestra república se crían sin virtud ni disciplina alguna, si no es la del tianguez o plaza de México y en otros vicios y aunque los padres los quisiesen dar alguna no hay en qué ejercitarlos: [...] no sé daquí a pocos años en qué han de parar por no tener salida ni ejercicio virtuoso en qué ocuparlos, parésceme $[\ldots]$ que $[\ldots]$ su majestad terná pocos amigos en los mozos que al presente hay [...] por evitar lo que desto podría subceder sería bien que mandasen hacer algunas casas fuertes y se proveiesen de las cosas necesarias y no se debería tener tanta confianza que diese ocasión a los súbditos que hagan lo que no deben porque las armas siempre suelen traer consigo la paz ${ }^{2}$.

Y hasta se podría aducir como prueba de que se percibía ya una marcada diferencia en la manera de hablar de peminsulares y criollos la siguiente afirmación — tan tremenda como común en su saña- de López de Velasco en 1572:

Todos [los criollos] son grandes y la color algo baja declinando a la disposición de la tierra; de donde se toma argumento, oue en muchos años, aunque los españoles no se hubiesen mezclado con los naturales, volverían a ser como son ellos: y no solamente en las calidades corporales se mudan, pero en las del ánimo suelen seguir las del cuerpo, y mudando él se alteran también, o porque por haber pasado a aquellas provincias tantos espíritus inquietos y perdidos, el trato y conversación ordinaria se ha depravado, y toca más prestc a los que menos fuerza de virtud tienen; y así en aquellas partes ha habido siempre y hay muchas calumnias y desasosiegos entre unos hombres con otros ${ }^{3}$.

${ }^{2}$ Citado en Marvyn Helen Bacigalupo, A Changing Perspective: Attitude. Toward Creole Society in New Spain (1521-1610), Tamesis Books, London, 1981 p. 7, que a su vez cita a Francisco del Paso y Troncoso, Epistolario de Nuev España, VI, p. 160.

${ }^{3}$ Juan López de Velasco, Geografía y descripción universal (1572), Estable cimiento Tipográfico de Fortanet, Madrid, 1894, citado en Bacigalupo, op cit., p. 55; las cursivas son mías. López de Velasco parece ser el primero eI emplear y definir el término criollo; en esta misma obra, en la sección "De lo 
El andalucismo de las hablas americanas es el marco de muchos de los estudios que buscan en el habla de los primeros pobladores el centro irradiador de los fenómenos que iban a definir y separar estas variedades americanas de las peninsulares. Así Claudia Parodi, en un análisis de 14 breves manuscritos de la ciudad de México escritos en 1523, sintetiza esta postura - sin suscribirse a ella- y afirma:

La mayor parte de los estudiosos del problema suponen que los conquistadores nivelaron sus diferencias dialectales para formar un núcleo lingüístico general, sevillanizado, cuya característica más importante, el çeçeo-zezeo, adquiriría la mayoría de los subsiguientes colonizadores [... ] Todos ellos, al extenderse por el continente, llevaban consigo la modalidad lingüística andaluzada, de ahí que se haya considerado a este primer período de la lengua castellana transplantada al Nuevo Mundo como la base del ulterior español de América ${ }^{4}$.

Frente a tan categórico pronunciamiento, Parodi demuestra que en América y en la Nueva España se encontraban todavía por esas fechas hábitos lingüísticos que reflejan la diversidad dialectal peninsular más que la nivelación americana. De hecho los informantes de Parodi apuntan más a una falta que a una presencia de nivelación.

$Y$ eso es lo que sorprende a Lope Blanch cuando compara los resultados de Parodi con los que él encuentra en la lengua de Diego de Ordaz, conquistador oriundo de Castroverde de Campos (León), quien debió de llegar a América a los veinte años y a la Nueva España a los cuarenta ${ }^{5}$. Frente a la "confusión" en las sibilantes de los documentos de Parodi, Diego de Ordaz presenta un sistema de "nítida distinción" (p. 42), aunque esta distinción se ve sólo en los manuscritos autógrafos y no en las cartas dictadas a amanuenses, en las que impera nuevamente la confusión.

españoles nacidos en las Indias", dice "criollo... que de madres y padres españoles... [nace] ... en... [Indias]".

${ }^{4}$ Claudia Parodi, "Para el conocimiento de la fonética castellana en la Nueva España: 1523. Las sibilantes", Actas del III Congreso de ALFAL, Publicaciones del Instituto de Lingüística, Puerto Rico, 1976, p. 115.

${ }^{5}$ Juan Lope Blanch, El habla de Diego de Ordaz. Contribución a la historia del español americano, UNAM, México, 1985, p. 9. El corpus consta de siete cartas autógrafas que escribe Diego de Ordaz en España entre abril de 1529 y agosto de 1530 a su sobrino Francisco Verdugo, residente en la ciudad de México. 
Margit Frenk, en la "Introducción"' a la obra Villancicos, romances, ensaladas y otras canciones devotas de Fernán González de Eslava (1534-c. 1603), español llegado a América a los veinticinco años de edad, analiza las sibilantes y encuentra que éste mantenía las distinciones que eran propias de un hablante castellano y que así se alejaba del uso imperante en la capital novohispana: " . . lejos de haber adoptado el habla americana, Eslava tenía una pronunciación distinta de la común a la mayoría de los españoles radicados en México"'6.

Cabe notar que lo que se desprende de estos estudios es que la "confusión" se da entre amanuenses y en la ciudad de México, mientras que la "distinción" se mantiene en el sistema individual de dos españoles que residieron en México. Entrevemos así el hilo conductor de lo que se intenta presentar en este trabajo: que en el México del siglo xvi se juntaban hablas de varias procedencias que ni se ajustaban fácilmente a unas normas lejanas -y digo normas porque en la península se discutía y se seguiría discutiendo las mismas cuestiones de lengua que aquí se presentan - ni constituían todavía una variante homogénea. Es des. de esa libertad expresiva de donde surgen, en México como er otras partes de América, los dialectos americanos.

Si bien es lugar común -y razonable - contrastar las mues. tras de habla como las anteriores con un sistema nivelado, no e: menos cierto que esta nivelación se basa en consideraciones $a$ pos teriori que pertenecen principalmente a las sibilantes. Pero en e fondo las discusiones acerca de las "confusiones", "sistemas ines tables", etc., a lo mejor no son sino un reflejo del escaso conoci miento que se posee de la lengua de los criollos en esa crítica eta pa formativa de las modalidades lingüísticas virreinales que de sembocarían en lenguas nacionales.

$\mathrm{Y}$ es por lo anterior que considero importante el estudio d la lengua de los contadísimos criollos que dejaron muestras de ella aun cuando no se ajustan al canon. Tal es el caso de Juan Suáre: de Peralta, cuyo Tratado del descubrimiento de las Yndias y su conquist (1589) se publicó recientemente ${ }^{7}$.

${ }^{6}$ Fernán González de Eslava, Villancicos, romances, ensaladas y otras can. ciones devotas, ed. Margit Frenk, El Colegio de México, México, 1989, p. 22

7 Juan Suárez de Peralta, Tratado del descubrimiento de las Yndias y su con quista (1589), ed., est. y notas de Giorgio Perissinotto, Alianza Editorial, Ma drid, 1990. El manuscrito se conserva en la Biblioteca Pública de Toledo : corresponde a la signatura núm. 302. La encuadernación es en piel clara : el tamaño de $19 \times 16 \mathrm{~cm}$. en cuartos de 179 fojas numeradas por el autor 
Aunque el nombre de Juan Suárez de Peralta figura en algunas historias de literatura colonial mexicana y hay quien lo considera, con cierta razón, precursor del cuento mexicano ${ }^{8}$, ningún investigador ha estudiado sus escritos con detalle. Ello se debe quizá a que su obra ha permanecido punto menos que desconocida hasta fines del siglo Xıx, cuando la historiografía de América se había completado y habían sido consagrados sus mayores exponentes. Entre los primeros que escriben sobre la vida de Juan Suárez de Peralta está don Justo Zaragoza, quien publica en 1878 bajo el título de Noticias históricas de la Nueva España el hasta entonces inédito Tratado del descubrimiento. . ., después de haberlo rescatado de los archivos de la Biblioteca Provincial, ahora Pública, de Toledo 9 . En 1949 Federico Gómez de Orozco reimprime en México esta edición con ortografía modernizada y con una "Nota preliminar" en la que aduce nuevos datos para fijar la fecha de nacimiento del autor ${ }^{10}$. Pero el que con más empeño se ha dedicado a rastrear la genealogía de la familia del cronista en los documentos de la época es el historiador Francisco Fernández del Castillo, cuyas notas sobre la familia de los Suárez permanecieron inéditas hasta 1980, cuando se publicaron con el título Doña Catalina Xuárez Marcayda ${ }^{11}$.

En la hermosa portada que abre paso al manuscrito del Tratado campean la firma y rúbrica de Juan Suárez de Peralta y, directamente abajo y centrado, se lee "Vecino y Natural de México".

Faltan, sin embargo, los folios 64 y 65 . En buen estado de conservación, sólo las primeras páginas han sufrido el abuso de algunos lectores; la encuadernación apretada hace difícil la lectura del final y comienzo de algunas líneas.

${ }^{8}$ Luis Leal, Breve historia del cuento mexicano, Manuales Studium, México, 1956, p. 21. En la Antología del cuento mexicano, Antologías Studium, México, 1957, p. 13, Leal moderniza un episodio del Tratado de Suárez de Peralta y lo incluye en su selección de cuentos novohispanos con el título "Suceso extraño de la hermana de Alonso de Ávila". Una sección del Tratado se incluye también en La conjuración de Martín Cortés y otros temas, sel. y pról. de Agustín Yáñez, UNAM, México, 1945.

${ }^{9}$ Imprenta de Manuel G. Hernández, Madrid. Zaragoza completa la edición con una introducción, una serie de notas, índices geográfico, biográfico y de palabras americanas.

${ }^{10}$ Secretaría de Educación Pública, México, 1949.

${ }^{11}$ Francisco Fernández del Castillo, Doña Catalina Xuárez Marcayda, Gosmos, México, 1980. Es importante señalar que este libro -producto de la historiografía decimonónica - trata principalmente de sucesos relacionados con la muerte de doña Gatalina y la consecuente acusación y juicio de uxoridicio levantados contra Hernán Cortés. En igual grado, el libro trata extensamente el árbol genealógico de los Suárez hasta los siglos posteriores. 
Por México hay que entender la ciudad de México y no el extenso territorio - hoy país - que se llamaba Nueva España. Y en lo de "natural", para que no haya duda acerca del lugar de nacimiento, en el capítulo XXIV lo reafirma diciendo: “ . . . en México, donde nací, puesto que mi padre era de Ávila y mi madre de Navarra'.

Juan Suárez de Peralta nace en la ciudad de México entre 1535 y 1540. La fecha de su nacimiento se sitúa en ese lustro por las indicaciones que el mismo autor proporciona en el curso de su narración. Así, al haber sido testigo ocular en las ejecuciones de algunos conspiradores, que tuvieron que haber ocurrido en 1542 o 1543, dice: "Yo los vi, siendo harto muchacho, y me acuerdo dieron mucha lástima, y oí decir morían sin culpa" (cap. XXII); el "harto muchacho" tendría entonces entre seis y ocho años. También afirma haber presenciado, siendo niño, la vuelta de la expedición de 1543 de Francisco Vázquez Coronado a las Siete Ciudades de Cíbola y haber visto los exiguos trofeos traídos de las míticas tierras: unos raídos cueros y una cabeza de bisonte americano, que describe minuciosamente en el cap. XXII (véase infra, nota 16). Y cuando en 1550 llega a la ciudad de México el segundo virrey Luis de Velasco y dispone la supresión del servicio personal al cual estaban tan acostumbrados los conquistadores, el cronista recuerda los tiempos de abundancia anteriores a la nueva ley: “. . . y yo vi en ese tiempo, que era muy muchacho, en casa de mi padre y tíos, derramar los cántaros de la miel para echar la nueva que los indios traían de tributo, porque no se perdiese" (cap. XXIV). Cabe poca duda que el "harto" y "muy muchacho" debió de nacer entre 1535 y 1540 . A lo anterior hay que añadir los testimonios de unos documentos de la época que claramente apuntan al año de 1537 como el que vio nacer a Juan Suárez de Peralta ${ }^{12}$.

El criollo Peralta se une así al reducido número de voces que obedecen al impulso de explicar su país natal a una sociedad que, es sabido, ignoraba en gran parte los usos y costumbres de esa tierra que tanto contribuyó a la grandeza imperial. Porque las voces que llevan la descripción de la realidad cambiante son, en casi todos los casos, de timbre peninsular. Escasísimas son las muestras indianas, y más escasas aún las indígenas. Para el caso de

12 Véase la "Nota preliminar" de Federico Gómez de Orozco en Juan SuÁrez de Peralta, Tratado del descubrimiento de las Indias, SEP, México, 1949, p. $\mathrm{x}$. 
México uno piensa en el indígena Hernando Alvarado Tezozómoc, el mestizo Diego Muñoz Camargo, Baltazar Dorantes de Carranza, Fernando de Alva Ixtlixóchitl y Bernardo de Balbuena, que aunque nacido en España, llegó a la Nueva España en tierna edad. No hay mucho más que nos permita comparar y ver cómo era percibida esa tierra por los que se habían criado en ella.

De ahí la gran importancia del Tratado del descubrimiento de las Yndias y su conquista. E. Anderson Imbert con mucho tino ha afirmado que el valor de esta obra, por imprecisos y hasta incorrectos que sean los datos históricos que maneja, estriba en que muestra "qué es lo que los primeros criollos creian tener detrás de sí en la historia de su tierra"'13. Leer el Tratado no es, entonces, sólo una búsqueda de nuevos datos sobre el primer siglo novohispano; es, por el contrario, ver la Nueva España y sus antecedentes históricos con la óptica muy especial del criollo. Y si el tratamiento del origen de los indios es simplista, es que ése era el entendimiento que de la cuestión se poseía en el México de 1550. Y si el Peralta historiador sigue muy de cerca sus pocas lecturas - Sahagún, Durán, Motolinía, Las Casas- no es menos cierto que su narración se eleva notablemente al disponerse a tratar temas netamente criollos: la vida cotidiana, las costumbres y convivencia con los indios, los acontecimientos políticos de los que fue testigo. No es con falsa modestia que confiesa en el capítulo 5: “... no tenía sino una poca de gramática, aunque mucha afiçión de ler historias y tratar com personas doctas".

\section{La lengua de Suárez de Peralta}

Notas sobre la ortografía

El periodo que va de fines del siglo $\mathrm{xV}$ a los primeros lustros del xviII se caracteriza, ya es sabido, por los cambios en la pronunciación y por el casi anárquico estado de la ortografía. Las apelaciones y exhortaciones de Nebrija, a juzgar por la gran variabilidad de grafías, quedaron voces clamantes in deserto.

Esta vacilación responde a dos hechos relacionados entre sí: el estado cambiante de los sistemas fonológicos de los romances peninsulares en un momento histórico en que se acentúan los con-

${ }^{13}$ Enrique Anderson Imbert, Historia de la literatura hispanoamericana, F.C.E., México, 1953, t. 1, pp. 56-57; las cursivas son mías. 
tactos entre ellos y se inicia su proyección hacia América y, en segundo lugar, el hecho de que el romance tardó notablemente, en general, en establecerse como tema de enseñanza en los centros escolares. La resultante falta de normatividad colectiva consciente en lo que a la ortografía se refiere, obliga a reconstruir, en cada obra o autor, el sistema que se emplea. Si en el caso de obras impresas la tarea se simplifica por la consistencia -relativa, claro- de la tipografía, en el caso de manuscritos autógrafos, copias, obras dictadas a amanuenses, etc., la tarea de extrapolar un sistema ortográfico se vuelve más difícil aún. De ahí que las conclusiones acerca del sistema fonológico deban su limitación a los escasos datos que arrojan los textos ${ }^{14}$.

\section{Vocalismo}

El vocalismo de Suárez de Peralta, sin apartarse de lo ya observado para esta época ${ }^{15}$, sí participa de las "vacilaciones"' entre vocales que se registran a lo largo del Siglo de Oro y que en algunos casos perduran hasta hoy. Si formas como ubidiencia y desculpa no sorprenden, de particular interés es la metafonía vocálica que resulta en la preferencia de formas que hoy están proscritas: çirimonias, posición ("posesión'), disierto, yntinçión, privinçia, cudiçia, auturidad, rimitieron, resuluçión, aunque no faltan los casos de disimilación: acomularon ("acumularon"), besitar ("visitar"). Es también frecuente la epéntesis de vocales y de nasal (Ingalaterra, tígue$r e$, tiguerillo, ansi) y, en no pocos casos, la prótesis con morfema $a$, que se añade quizá por ultracorrección: alesnas (por leznas " . . . los cuernos como de un palmo, muy agudos, que pueden servir de alesnas") 16 , aforrado (" . . . una ropa de damasco aforrada en pieles de tiguerillos, ques un aforro muy lindo y muy hidalgo"'), asen-

${ }^{14}$ Para una interesantísima y reveladora presentación de la cuestión ortográfica, es imprescindible el libro de Eva María Bravo García, El español del siglo xvii en documentos americanistas, Ediciones Alfar, Sevilla, 1987, pp. 59-71.

15 Véase, por ejemplo, Rafael LaPeSA, Historia de la lengua española, Gredos, Madrid, 1984, pp. 280-281.

16 No puedo dejar de reproducir el pasaje en el que el autor relata, como testigo ocular, la vuelta de una de las expediciones que se enviaron en busca de las Siete Ciudades; lo que traen al retorno no es oro, sino las pieles del bisonte americano. Posiblemente sea la primera descripción de este animal: "En todo esto dijo berdad, porque ay en aquella tierra los montes que dijo, y ganados, espeçialmente de bacas; pero no son como las de acá, porque bí cueros de los que trujeron estos soldados, y son muy diferentes. Tienen el pezcueço 
tado ("abía de ser descalço y asentado de chıquillas"), atentado ("auiendo primero atentado con los dedos el lugar por donde le a de dar'), sin faltar, claro está, ejemplos contrarios: probechó (" ". probechó a todo el mundo que fue a la isla Española"), justiçiar (varias veces " . . que era el que entendían tenía más riesgos y al que primero abían de justiçiar").

\section{Consonantismo}

Las sibilantes. Son pocas las trazas de la antigua oposición entre sordas y sonoras que la ortografía medieval representaba con las grafías - $s^{-}$y $-s s^{-}, s-$, $-s$. Peralta escribe $-s^{-}$para representar los fonemas / $/$ / y / $/$ / unificados: fertilísima, cosas, dexasen, metiesen, munchísimos, etc.; escribe -ss- sólo en dos ocasiones, una de ellas antietimológica: opressos, pero también ossó y osó. El ensordecimiento de la $z$ por otro lado, se evidencia sólo con una ocurrencia de deçir y una de dişen, además de los siempre problemáticos numerales, que siempre se escriben -çientos para reflejar la revisión ortográfica del medieval -zientos.

La oposición sorda/sonora entre / $\mathrm{z} /$ y / $\breve{s} /$, ortográficamente $j, g, x$ y con seguridad fricativas palatales, no se da en el Tratado que, en marcado contraste con los sistemas de Ordaz y González Eslava, parece haber nivelado los contrastes: aconsexaron y consejo, xamás, lixítimamente ("legítimamente"), xuezes ("jueces"), exiçios ("egipcios"), y también baje (de "bajar"), truje, pajaros, aguxerillos, deuaxo ("debajo"), texuelo; de particular interés es esecución, esecutase, que también escribe ejecuçión y ejecutar. La grafía $j$ frecuentemente alterna con $g$ en palabras como genteljente, gentiles/jentiles, aunque favorece la $g$. Esta nivelación concuerda con lo apuntado por Antonio Alatorre, quien afirma que la pronunciación innovadora y desfonologizadora de Burgos había cundido en Castilla la Nueva en la segunda mitad del siglo Xvi ${ }^{17}$.

La lengua del Tratado sugiere un sistema de sibilantes marca-

y frente lleno de lana, que no pareçen sino leones coronados, los cuernos como de um palmo, muy agudos, que pueden seruir de alesnas"' (Tratado, cap. 22).

17 Antonio Alatorre, Los 1001 años de la lengua española, F.C.E.-E1 Colegio de México, México, 1989, p. 253. Quizá no sea superfluo recordar aquí que la velarización de esta palatal fricativa, $/ \check{s} />|\chi|$, aunque documentable desde principios del XVI, no se extiende a todas las capas sociales hasta muy entrado el XVII. Véase PaUl M. Lloyd, From Latin to Spanish, American Philosophical Society, Philadelphia, 1987, pp. 342-345. 
damente distinto del de González de Eslava y Ordaz, resucitando así la cuestión de la cronología del cambio. Amado Alonso ${ }^{18}$ sostiene que el ensordecimiento ocurrió alrededor del año $1500 \mathrm{o}$ antes, mientras que otros estudiosos sostienen que tal cambio ocurrió a mediados del siglo $\mathrm{XVI}^{19}$. Los datos que emanan del texto que analizamos postulan que para 1589 el ensordecimiento de las sibilantes se encontraba en un estado muy avanzado con tan sólo esporádicas muestras de las antiguas oposiciones entre $/ \dot{\mathrm{s}} / \sim / \dot{\mathrm{z}} / \mathrm{y}$ $\mid \breve{s} / \sim / \mathrm{z} /$. El estado del contraste entre $/ \hat{\mathrm{s}} / \mathrm{y} / \hat{\mathrm{z}} /$, por otro lado, no está del todo claro. Las pocas documentaciones de las grafías - $\varsigma^{-}$ donde era de esperarse $-z$ - (deçir y diçen), no justificarían hipotetizar el ensordecimiento sistemático y cobran aún menos importancia a la luz de la mucho más abundante - $z$ - etimológica: dezir y fazer (en toda su gama morfológica), azia (hacia), rayzes, juizio, narizes, naturaleza, razón, reduzen, etc. De manera que los datos obligan a dar por vigente aun la distinción entre la sorda / $/$ / y la sonora $/ \hat{z} /$. Una vez más cobran sentido las palabras de Juan de Córdoba en su Arte en lengua zapoteca (1578):

Entre nosotros y en nuestra España es lo mesmo: que los de Castilla la Vieja dizen aşer, y en Toledo hazer; y dizen xugar, y en Toledo jugar; y dizen yerro, y en Toledo hierro; y dizen alagar, y en Toledo halagar.

La afirmación categórica del ensordecimiento de / $/$ / y /ž / contrasta, desde luego, con la no mención, por parte del fraile misionero, de la oposición entre -s- y -ss-. Amado Alonso sugiere que han de haber seguido el patrón de los otros dos pares y mantenido la distinción ${ }^{20}$, mientras que Parodi interpreta el testimonio de Juan de Córdoba al pie de la letra: no se hace mención de la distinción porque ni siquiera en Toledo se diferenciaba entre -sp. 92.

${ }^{18}$ De la pronunciación medieval a la moderna en español, Gredos, Madrid, 1976,

19 Véase por ejemplo, D. L. CANField, "Spanish American Data for the Chronology of Sibilant Changes", $H, 35$ (1952), p. 27; y Diego Catalán, "The End of the Phoneme / $z$ / in Spanish", Word, 13 (1957), p. 287.

${ }^{20}$ Dice, op. cit., p. 23: "Nada se dice aquí [en Juan de Córdoba] de -sy -ss-, pero la historia de las parejas $s-s s, z-\varsigma$ y $j$ - $x$ está coordenada casi en todas partes, la de $s-s s$ y $z-\zeta$ en todas, de modo que, por lo menos como guía provisional, es lícito extender a la pareja s-ss lo que el P. Córdoba decía de las otras dos: Toledo (y el Sur) conservaba la correlación de sonoridad en una época en que Castilla (y el Norte en general) la había perdido". 
y -ss-, lo que reduciría el sistema a una apicoalveolar / $\mathbf{s} /$ opuesta a una predorsoalveolar /s/y, posiblemente, rezagos de una /z/ sonora ${ }^{21}$.

En lo que se refiere a las articulaciones africadas, mientras que Lope Blanch propone que Diego de Ordaz las mantenía con regularidad, Parodi sostiene que esta articulación nunca llegó a las Américas. El criollo Peralta, quien con cierta probabilidad no sentía ni la presencia ni la presión de una fuerte norma peninsular, exhibe un sistema gráfico-fonético bastante caótico en lo que a las fricativas/africadas se refiere, aunque parece favorecer las pronunciaciones fricativas. Escribe desendençia, Ynquisisión, posisión ("posición"), susę̧ión, sę̧aba ("cesaba"), aunque por lo general mantiene la grafía $z$ para lo que probablemente era ya articulación fricativa pero ocasionalmente sonora: juizio, juezes, bezes, di$z e$, razón, etc. ${ }^{22}$ Las muy numerosas grafías con $s$ donde se esperaría $\ell$, junto con las ultracorrecciones, mientras que apuntan claramente a una articulación fricativa ${ }^{23}$, nos obligan a volver a preguntarnos si la desfonologización de /s/ y / z/ resultaría en una articulación apicoalveolar que contrastaría entonces con la modalidad dorsoalveolar proveniente de la fricatización de la africa$\mathrm{da} / \hat{\mathrm{s}} / \mathrm{y}$, eventualmente, de la $/ \hat{z} /$. No hay indicio alguno de que Peralta distinguiera entre la $s$ proveniente de las antiguas $/ \dot{\mathrm{s}} / \mathrm{y}$ $/ \dot{z} /$ y la $s$ que es el resultado de la pérdida del elemento oclusivo de la /ŝ/: grafías como seçaba ("Oy dezir que tampoco seçaba [cesaba] la tormenta"), Medinaçidonia, Ynquisisión, sierra y çierra ("... y auiendo pasado la sierra neuada del bolcán. Estas dos son çierras que pareçen, según su altura, se comunican con el çielo"), çuçedió (" aunque no le çuçedió en la bentura como en el estado y en la hazienda"), françeces (una vez) y françeses (tres veces), çuzios, etc. insinúan una fase bastante avanzada de nivelación entre las sibilantes, que se podría reducir a una dorsodental fricativa sorda /s/ con restos de una articulación sonora para la probablemente fri-

21 Op. cit., p. 23.

22 También es digno de apuntar que escribe las palabras nahua cocoloztli y teponaztle invariablemente con $z$, sonido que ante $t$ era seguramente sordo, aunque posiblemente africado todavía; pero escribe tiçatl (tiza " . . . un terrón de tierra muy blanca, ques a manera de greda, saibo ques en estremo blanquísima... que llaman los yndios tiçatl..."), que corresponde a una velar africada sorda en la lengua indígena.

${ }^{23}$ Medinaçidonia, minsión ("mención"), desendençia ("descendencia"), çuzios ("sucios"), Ynquisisión, sierra y çierra ("sierra"), blanquisco, persuaçión, folicita ("solícita"), çu̧̧edió ("sucedió"), françeces ("franceses"), Baltasar, sę̧aba, Falses ("Marqués de Falçes"). 
cativa $-z$-. No será demasiado aventurado afirmar, entonces, que el habla de los criollos de la ciudad de México en el último cuarto del siglo XVI era netamente seseosa.

De $F>H_{1}>\emptyset$. La aspiración de la / h/ procedente de /f/ latina, que Lope Blanch da como normativa en el habla de Ordaz y que Wargit Frenk registra como propia del dialecto toledano que propone para González de Eslava, se ha reducido a cero fonético en el sistema del criollo novohispano Peralta. Aunque no son raras las grafías que podrían apuntar al mantenimiento de la aspiración, la omisión de $h<f$ y la ultracorrección denuncian la pérdida. Así herró ("Herró la isla y pasóse de largo sin berla"), huso (" . . y toman un huso, que llaman malacate...", "Como rehilan el huso..."), uso ("Estos usos an de andar rehilándolos..." ), olgó ("Olgó dello muncho y luego despachó a unos capitanes. . .'), alcón (". . . y aunque le cueste un alcón munchos reales, no quedará sin él"), aleones, halcones ("Aun los aleones, como son neblíes, sacres, aletos, baharies, y otras aues de rapiña...', “' ... donde se traen aquellas cargas de halcones muertos...'”) y azendado, azienda al igual que onor, ábito, eladas, onrada, etc. Los derivados de hacer se suelen rendir con $h$, pero abundan las grafías azer ("Esta es la justiçia que manda azer su magestad...", “. .. quellos fueron sentençiados a ahorcar, azer cuarto y arrastrar...' ') ${ }^{24}$.

$B, U, V$. No hay trazas de la antigua distinción entre / $\mathrm{b} / \mathrm{bilabial}$ y /v/ labiodental. Aunque sabemos que hubo defensores de la articulación labiodental hasta entrado el siglo $\mathrm{xvn}^{25}$, el mismo Sebastián de Covarrubias (1611) la daba por perdida ${ }^{26}$. Las grafías más comunes que emplea este criollo para las consonantes bilabiales, tanto en su realización fricativa como oclusiva, son $b$ y $u$. El autor alterna entre grafías como "nueba" y "nueua", " auer", y "aber". La $v$, de baja frecuencia en los primeros capítulos del

${ }^{24}$ Recordemos lo que a propósito de la $h$ decía JuAn de Valdés, Diálogo de la lengua, ed. J. M. Lope Blanch, Castalia, Madrid, 1978, p. 97: “ . . unos la ponen adonde no es menester, y otros la quitan de donde stá bien. Pónenla algunos en era, havía y han, y en otros désta calidad, pero esto házenlo los que se precian de latinos; yo, que querría más serlo que preciarme dello, no pongo la $h$, porque leyendo no la pronuncio".

${ }^{25}$ Y más tarde. La Ortografía de la Real Academia en 1741 advierte: “El confundir el sonido de la $b$ y de la $v$, como sucede comúnmente, es más negligencia o ignorancia de los maestros y preceptores, y culpa de las malas costumbres adquiridas en los vicios y resabios de la educación doméstica y de las primeras escuelas, que naturaleza de sus voces".

${ }^{26}$ Alatorre, op. cit., p. 256. 
Tratado, se ve favorecida por el autor conforme va avanzando la redacción. Quizá sea esto un indicio de que la obra se escribió en diferentes épocas o en lugares donde imperaba una norma distinta de la que estaba en boga cuando comenzó su relación. Hacia la mitad de la obra, Suárez de Peralta empieza a emplear la $v$ con valor tanto vocálico ("vno" por "uno") como consonántico (escribe "Velasco" cuando en varias ocasiones anteriores había escrito "Belasco"). El lector ya no se encontrará desconcertado ante las grafías "seruiçio", "aprouechamiento", "captiuos", “triuus"' (tribus), "berso"' (verso), "suabe" (suave), después de unos pocos párrafos.

Yeísmo. Aunque la desfonologización de / / / y /y/ se documenta en la península desde la Edad Media y en la Nueva España ya en $1527^{27}$, los filólogos están de acuerdo en que el cambio fue lento $\mathrm{y}$, durante siglos, de carácter esporádico. Suárez de Peralta, cuya ortografía, como hemos visto, delata casi siempre su fonética, es sorprendentemente "distinguidor" de $l l$ y $y$, lo que nos induce a pensar que la distinción correspondería a una diferencia fonética: "A los quales hallaron en un montezillo de um pueblo que llaman Questlauaca"'28.

Grupos cultos. La reducción o mantenimiento de grupos consonánticos de origen culto es una discusión que surge de la conciencia de las formas etimológicas y que no se resuelve hasta el siglo XvIII, cuando la Academia opta por la fidelidad a la pronunciación latina, aun cuando la tendencia había sido hacia la reducción tanto en el nivel culto como en el popular. Y si el peso de la Academia se ha hecho sentir en las hablas cultas, no ha sido así en las capas populares, que siguen reduciendo ahora como en el siglo Xvi. Suárez de Peralta es claro ejemplo de ambas tendencias: la de conservar los grupos latinos para quizá alardear de una formación clásica que no tenía y la de reducir los grupos conforme a la pronunciación vigente. Apuntamos dotor, dotrina, solenidad, ynsinias, pronosticauan, açetar, espetáculo, retificados, esibir ("exhibir"), dinidad, fator, seta ("secta"), bitoria ("victoria"), infiçión ("infección"), tras-

${ }^{27}$ Claudia Parodi, "El yeísmo en América durante el siglo xvi", $A L M$, 15 (1977), 241-248. Véase también el tratamiento de la cuestión en Alato RRE, op. cit., pp. 254-255.

${ }^{28}$ Es de notar, sin embargo, que sí escribe "ofrecellas" (ofrecerlas), "sacrificallo" (sacrificarlo), "açotallos y tresquilallos" (azotarlos y trasquilarlos), "dezilles" (decirles), etc., según la moda que imperaba principalmente entre andaluces, murcianos, toledanos y gente de la corte; véase R. LAPESA, op. cit., pp. 391-392. 
parente, etc., pero consignamos también ecfecto, delicto, escripto, súbditos, doctrina, subjetado, que alterna con la forma reducida ("no para castigarles sus culpas, sino para robarles sus bienes o sujetarlos a su señorío. Lo qual no se puede entender por nuestros reyes que, puesto que ayan subjetado los yndios y echado de su señorío") $)^{29}$.

Juan Suárez de Peralta, cronista de Martín Cortés y del levantamiento y degüello de los hermanos Ávila, "cavallero de la tierra" cuyo estilo de narrar tiene la frescura de la inmediatez, reúne en su habla tanto las tendencias transoceánicas que le llegarían por su antes mencionada "afiçión de ler historias y tratar com personas doctas", como los rasgos difusos e indecisos de una modalidad lingüística en formación y, por lo tanto, llena de contradicciones internas, ora innovadora, ora conservadora, pero sí - por lo anterior - sumamente característica e individual. Al igual que su tratamiento de los grupos consonánticos cultos, Peralta tamiza y escoge, echa mano de latinismos y de aztequismos, se deja arrastrar por la norma a veces y en ocasiones se aparta de ella porque no es como se habla en la ciudad de México. En comparación con los otros textos de la época, es obvio que el sistema para él vigente no es el mismo que el de los peninsulares residentes en México. Y es allí donde hay que buscar el centro irradiador del español mexicano, el del habla espontánea, casi descuida$\mathrm{da}$, de sus criollos ${ }^{30}$.

José Joaquín Blanco ${ }^{31}$, en busca de los rasgos del primer criollismo, contrasta la actitud hacia la Nueva España por parte de los primeros conquistadores y avecindados con la de los novohispanos que les sucedieron. Mientras que aquéllos no sentían ningún "amor patrio por un país que, efectivamente, a veces les daba riquezas, posición y comodidades. . . pero que les parecía una tierra segundona y poco admirable', éstos, los primeros criollos del Xvı comienzan a exhibir el orgullo hacia su tierra que desem-

${ }^{29}$ Rafael Lapesa, Historia de la lengua española, Gredos, Madrid, 1984, p. 390, dice: "Todo el período áureo es época de lucha entre el respeto a la forma latina de los cultismos y la propensión a adaptarlos a los hábitos de la pronunciación romance [...] Ni siquiera a fines del XVII existía criterio fijo; el gusto del hablante y la mayor o menor frecuencia del uso eran los factores decisivos".

${ }^{30} \mathrm{El}$ presente trabajo sólo trata de la fonética del español novohispano. En otros trabajos en curso se estudiarán algunos rasgos morfosintácticos y léxicos que sustentarán la hipótesis de un español mexicano en vías de definición.

${ }^{31}$ La literatura en la Nueva España, Cal y Arena, México, 1980, p. 219. 
bocaría en la reivindicación y rebeldía de los siglos sucesivos. En nuestro criollo este orgullo y apego a la tierra (véase el epígrafe que abre este ensayo) llega a veces hasta la comunión con los indios, hacia quienes demuestra una benevolencia que raya en afecto, especialmente cuando se hermanan con los europeos tanto en los vicios como en la religiosidad:

. . . siendo yo correjidor por su majestad castigué a munchos, que era la pena ordinaria por borrachos açotallos públicamente y tresquilallos las caueças (cap. 2).

[...]

Es de admirar de la manera que la cristiandad a entrado en los yndios, espeçialmente en los mejicanos, ques diferente lengua y probinçia de las demás de la Nueba España, más cortesana y más pulida. Aun la gente más allegada a razón, la cual está ya tan españolada que en muchas cosas nos semejan (cap. 3).

Presento las muestras anteriores y la que cierra este homenaje por dos motivos. Primero para transmitir el tono de la lengua de Suárez de Peralta en un texto más extenso que las palabras y frases que se emplearon para delinear el sistema fonético, y, segundo, para insinuar que el criollo empieza a gravitar más y más hacia su tierra natal y definirse así como mexicano. Y no cabe duda que Juan Suárez de Peralta, aun cuando se afirma indudablemente español, es un criollo en el que la conciencia de otredad se revela en el pasaje siguiente donde narra, con la tranquilidad y convicción del justo, la vana búsqueda del tesoro de Moctezuma.

Unos dizen que lo echaron en la laguna, y otros que lo enterraron y está escondido. Yo oy dezir a un yndio biejo que llanamente lo lleuaron a la laguna, y que el demonio se lo ayudó a llebar porque los cristianos no le gozasen. Cuádrame que le echaron en la laguna, porque si le tubieran enterrado y escondido, ¿es posible que no ubieran dado con él tantos años a que poseen la çiudad cristianos y que comunican con los yndios muy familiarmente, espeçial los naçidos en México, a quien los yndios tienen por hijos, y sus mujeres an criado los más a sus pechos, que no les ubieran descubierto algo? Y dádibas que an dado a los biejos, todos los más dezían [que] la laguna le poseya.

Giorgio Perissinotto University of California, Santa Barbara 
